\title{
The relationship between generalized paroxysmal E.E.G. discharges and various test situations in two epileptic patients
}

\author{
BARBARA TIZARD AND J. H. MARGERISON \\ From the Institute of Psychiatry, Maudsley Hospital, London
}

This investigation was carried out on two patients suffering from so-called primary subcortical epilepsy. Serial studies were made both of variations in the amount of paroxysmal electrical activity recorded from the brain during the performance of psychological tests and of changes in test performance in the presence of paroxysmal discharges.

There is no doubt that changes in the alpha rhythm can be shown to accompany alterations in behaviour in all subjects. The paroxysmal E.E.G. discharges recorded from epileptics have rarely been studied from this point of view. It is, however, widely held that petit mal attacks do not occur randomly with respect to mental state. Lennox and Lennox (1960), who tended to equate the electroencephalographic dysrhythmia with the clinical ictus, considered that petit mal attacks occur less often when the patient is kept occupied. According to Pond (1961), petit mal attacks may be precipitated by emotional disturbance. In the present investigation a series of E.E.G. examinations and of psychological tests was carried out pari passu in order to determine whether there were systematic differences in the amount of paroxysmal activity recorded in different test situations. Such differences as were found were then further explored in an attempt to discover the factors responsible for them. Autonomic function seemed to be one variable of possible significance, and respiration and pulse rate were therefore recorded throughout.

The investigation was also planned to permit the study of changes in test performance during the occurrence of generalized paroxysmal discharges. Patients were selected whose E.E.G. records contained brief generalized wave-spike discharges, without clinical accompaniments. A distinction is often drawn (Kiloh and Osselton, 1961) between such 'inter-seizure' discharges and the electrical disturbance associated with petit mal attacks. However, brief discharges do not differ qualitatively in their E.E.G. parameters from bursts of longer duration and might be expected to have behavioural correlates which could be measured by a more $\overrightarrow{0}$ refined method than clinical observation. A number of studies have been made of responses to psychological tests during brief discharges but the findings are conflicting. Schwab (1941) and Cornil, Gastaut, and Corriol (1951) stated that reaction times are delayed, but Prechtl, Boeke, and Schut (1961) found is no impairment in the rate of performance on a seriad $\omega$ reaction test, and Milstein and Stevens (19619

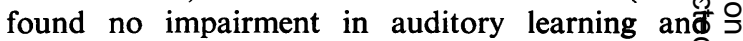
avoidance conditioning during brief generalize discharges. Kooi and Hovey (1957) recorded spontaneous paroxysmal discharges in epilepticis during intelligence testing. They stated that althoug the questions were usually heard an adequat $\overrightarrow{0}$ solution was never given during bursts of bilaterat $\omega$ synchronous activity. However, they do not state the duration and number of the discharges, and it is not clear whether the reported association is significant.

Although these findings are conflicting, there are many differences between the studies in variables which may be important. Both Milstein and Stevens and Cornil et al. studied the correlates of discharges induced by photic stimulation, which may be neurophysiologically distinct from spontaneous paroxysmal activity. Other variables of possible importance in determining the effect of paroxysmal discharge on test performance are the nature of the test, the form of the discharge, the age and intelligence of the patient, and the presence or absence of manifest cerebral damage. If spontaneous generalized discharges are studied it is extremely difficult to control these other variables, since there are rarely sufficient patients with frequent discharges available to form homogeneous groups. In the present investigation it was decided to make intensive studies of a few patients with brief spontaneous 
discharges, using two psychological tests. By using serial studies it was hoped to investigate an additional problem of theoretical and practical importance, that is, whether the occurrence of very frequent generalized paroxysmal discharges affects test performance between discharges.

\section{SUBJECTS}

A search was made in the epileptic ward and out-patient clinics of the Maudsley Hospital for patients with minor epileptic attacks of subcortical origin, whose E.E.G. records showed frequent, spontaneous, brief bursts of bilaterally synchronous generalized wave-spike discharge, each discharge having a clearly demarcated beginning and end. Only two patients were found who fulfilled these criteria. The first, C.M., was a girl of 23, with a history of many minor attacks daily since the age of 6 months and occasional major seizures. The minor attacks were characterized by a hesitation in speech and a fluttering of the eyelids. There was no family history of epilepsy and there were no focal clinical or E.E.G. features. Frequent bursts of symmetrical bilateral $3 \frac{1}{2}-4 \frac{1}{2} \mathrm{c} / \mathrm{s}$ wave-spike complexes of atypical form, lasting from $\frac{1}{2} \mathrm{sec}$. to $6 \mathrm{sec}$. were seen in her E.E.G. record. She had a full-scale Wechsler I.Q. of 86 , a verbal I.Q. of 89 , and a performance I.Q. of 85 .

The second subject, A.S., was a woman of 62 with a history of infantile convulsions, occasional major seizures, and many minor attacks daily characterized by an arrest of speech and fluttering of the eyelids. There were no focal clinical or E.E.G. features. Two of her seven siblings were epileptics. Her E.E.G. showed very frequent bursts of symmetrical high-voltage 3-4 c/s wave-spike complexes, usually lasting from one to six sec., separated by periods of relatively normal activity. Her full-scale Wechsler I.Q. was 64, verbal I.Q. 69, and performance I.Q. 63. Psychological testing showed no evidence of a memory deficit. Her A.E.G. was considered normal, and the results of investigations of blood, urine, and cerebrospinal fluid were negative.

In both patients it was noted that the briefer discharges were without detectable clinical accompaniments and after them the patients did not report any seizures.

\section{METHOD}

An eight-channel Edison-Swan mark III machine was used to record E.E.G. activity (five channels), E.C.G., respiration, and test responses during the performance of simple psychological tests (Fig. 1). The patient was seated comfortably at a table and tested under standard conditions at the same time each day for 10 days. In order to increase the amount of wave-spike activity, the amounts of anticonvulsants were cautiously reduced during the investigation. The first day was regarded as a training session, and only the data from the subsequent days were included in the analysis. A daily baseline measure of generalized bilateral paroxysmal activity was obtained from two 10-minute periods of recording carried out immediately before and after the psychological tests.

\section{TESTS}

Two tests were used, each lasting for 20 minutes and presented in alternate order each day. The first, called here the 'tape test', resembles one on which Mirsky, Primac, Marsan, Rosvold, and Stevens (1960) found 'centrencephalic' epileptics inferior in performance to focal cortical epileptics and normal controls. A similar test was found useful by Williams, Lubin, and Goodnow (1959) in studying the effect of loss of sleep. The second test used, here called the ' 5 -lights test', resembles one used by Wilkinson (1958) to study the effect of loss of sleep. Both tests are simple enough for patients of dull intelligence and provide a repetitive and continuous task which permits the statistical assessment of the correlates

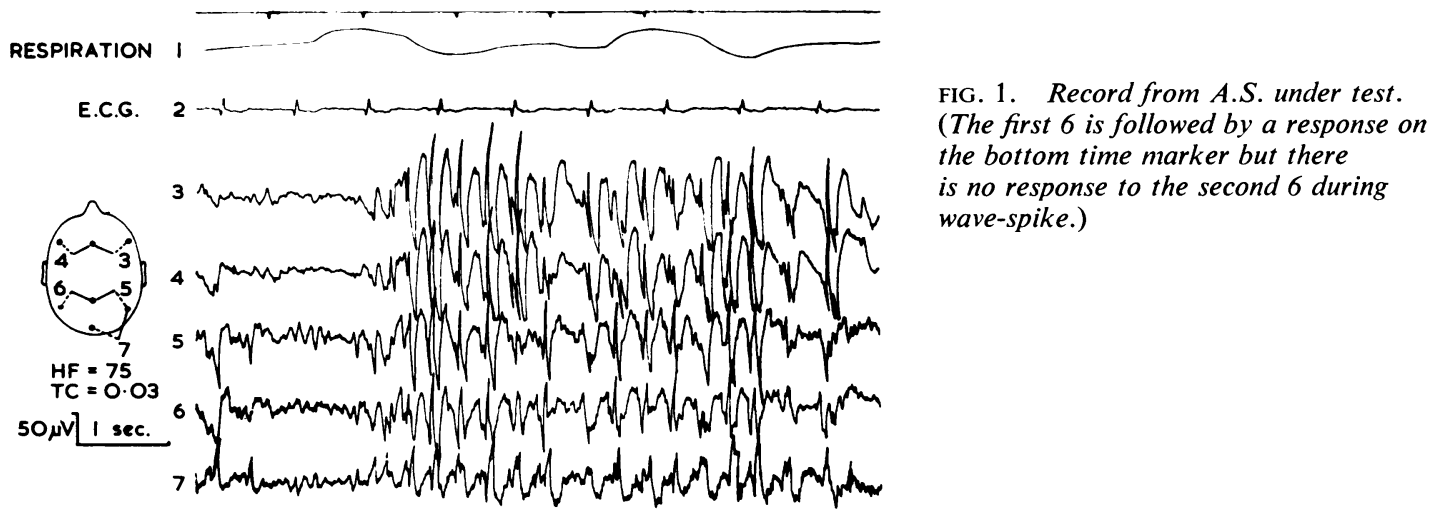

TAPE

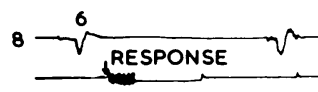


of spontaneous wave-spike activity. With both tests stimuli and responses, including errors, can be recorded on the E.E.G. tracing.

The tape test is paced, that is, the time available to respond is determined by the experimenter and is severely limited. The subject is asked to listen to a recorded series of numbers, from 1 to 9 , randomly presented, read at the rate of two a second. The task is to press a bulb as soon as possible whenever the number 6 is heard. The test was scored for errors of omission.

The 5-lights test is 'self paced', that is, the subject works at his own rate. Five small light bulbs are arranged in a semicircle on a board. When a centre button in the middle of the board is pressed one or other of the bulbs lights up. The light is put out by pressing a button adjacent to it. The subject is instructed in putting on and off the bulbs and asked to repeat the sequence as quickly as possible until told to stop. The order in which the bulbs light up is randomized. Two sets of scores were used: (1) response times, i.e., the intervals between successive pressings of the centre button measured in millimetres ( $3 \mathrm{~cm}$. $=1 \mathrm{sec}$.), and (2) errors, i.e., pressing the wrong peripheral button.

\section{RESULTS}

RELIABILITY OF MEASURE AND DAY-TO-DAY VARIATIONS IN WAVE-SPIKE DISCHARGES In the case of the first patient, C.M., the total number of seconds of wave-spike discharge in two records was measured independently by two scorers. One reported totals of 141 and 149 seconds, the other of 139 and 142 seconds. This agreement was considered adequate. In the case of the second patient, A.S., the reliability of measuring individual discharges was considered. A correlation of +0.94 was found between two independent estimates of the length of 10 of this patient's discharges.

There were great variations from day to day in the total amount of wave-spike recorded during 20 minutes' resting. In the case of C.M. the range was from 22 to 195 seconds, and no clear relationship could be seen between the amount of activity and the anticonvulsant régime. In the case of A.S. the range was even larger, from 28 to 777 seconds, the wave-spike recorded increasing as anticonvulsants were reduced. Because of these large variances a logarithmic transformation of the scores was made before tests of significance were applied.

DIFFERENCES IN WAVE-SPIKE RECORDED DURING DIFFERENT ACTIVITIES It was first established that with both patients there was no significant difference between the number of seconds of wave-spike recorded during the first and final rest periods. A daily resting value for wave-spike discharges was therefore calculated by summing the duration in seconds of discharges recorded during these two periods, and the duration in seconds of wave-spike discharges recorded during testing was compared with this value. In both patients significantly fewer wave-spike discharges were recorded during the 5-lights test than at rest and significantly more during the tape test than at rest (Table I). In both patients the proportion of wave-spike lasting less than three seconds was significantly greater during the 5-lights test than at rest $\left(\chi^{2}=9.4, \mathrm{P}<0.01\right.$ for C.M., $\chi^{2}=55.6, \mathrm{P}<0.001$ for A.S., d.f. $=1$ ) bue no significant difference was found between the duration of discharges in the tape test and at rest

EFFECT OF WAVE-SPIKE DISCHARGES ON PERFORMANCE OF TAPE TEST Both patients made significantly more errors of omission during wave-spike discharges than would have been expected by chance $\left(\chi^{2}=11 \cdot 5\right.$ $\mathrm{P}<0.001$ for C.M., $\chi^{2}=1169.0, \mathrm{P}<0.001$ for A.S., d.f. = 1). However, the performance of C.M. was much less affected by discharges than was that of A.S. C.M. responded to $76 \%$ of the ' $6 \mathrm{~s}$ ' that occurred during discharges, A.S. to only $20 \%$. When a wave-spike discharge lasted less than $1 \frac{1}{2}$ seconds the number of errors of omission made by both patients did not exceed the number that would have been expected by chance.

TABLE I

WAVE-SPIKE DISCHARGES DURING DIFFERENT ACTIVITIES

Wave-spike Discharges (sec.)

$\begin{array}{lll}\text { Patient } & \text { S-Lights Test } & \text { Rest } \\ \text { C.M. } & \text { Mean 34, range 7-87 Test } \\ \text { A.S. } & \text { Mean 79, range 11-283 }\end{array}$

$=$ Tests made on logarithmically transformed data 
TABLE II

RESPONSE TIME AND WAVE-SPIKE DISCHARGES

Wave-spike Discharges (sec.)

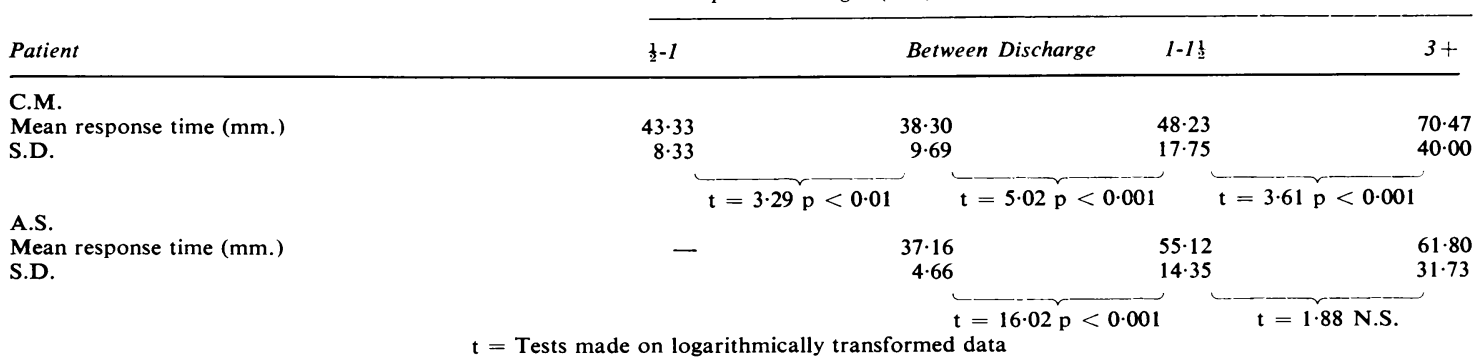

EFFECT OF WAVE-SPIKE DISCHARGES ON PERFORMANCE OF 5-LIGHTS TEST Both patients tended to continue working at the test, notwithstanding the appearance of wave-spike, but both worked more slowly. Table II shows that for C.M. response times were slowed during wave-spike discharges lasting only $\frac{1}{2}$ to 1 second. A.S. had only two discharges lasting less than 1 second. In both patients wave-spike lasting 1-1 $\frac{1}{2}$ seconds was accompanied by a highly significant slowing in response time.

Since performance was slowed during discharges one might have expected that fewer buttons would be pressed on days when it was increased. This was not the case, for the correlation between the total number of buttons pressed during a test session and seconds of wave-spike discharges recorded during the test was very low and not significant. It appears, therefore, that between bursts of wave-spike the patients were able to compensate for the periods of slowing. However, in the case of A.S., on the two days when very large numbers of wave-spike discharges were recorded during the 5-lights test (173 and 283 seconds) there was a decrease in the total number of buttons pressed.

A.S. not only worked more slowly during wavespike discharges but made significantly more errors at these times than would be expected by chance $\left(\chi^{2}=77 \cdot 0, \mathrm{P}<0.001, \mathrm{~d} . \mathrm{f} .=1\right)$. This was not true of C.M. who made very few errors at any time.

PERFORMANCE BETWEEN DISCHARGES There was no evidence that the occurrence of even very large numbers of wave-spike discharges impaired performance between discharges. Both patients' performance between discharges improved steadily from day to day on all the measures tested. The mean number of errors of omission between discharges made by A.S., for example, fell from 3.03 on the second day (12 sec. wave-spike discharges during test) to 0 on the final day (844 sec. wave-spike discharges during test). On the 5-lights test her mean response time between discharges during the first three minutes of the test fell from $41.7 \mathrm{~mm}$. on the second day (11 sec. wave-spike discharges during test) to $36.7 \mathrm{~mm}$. on the final day (284 sec. wavespike discharges during test).

The possibility, however, remained that performance immediately before and after a discharge might have been disturbed. Accordingly the duration of the final three response times before each wave-spike discharge and the first three response times after each discharge were compared with the mean response times recorded in the remainder of the period between discharges. In neither patient was there any significant increase in the response times before wave-spike discharges, but in the case of A.S. there was a significant increase in the first response time afterwards $(\mathrm{t}=2.4, \mathrm{P}<0.02)$. In this connexion, however, it should be pointed out that the cessation of a wave-spike discharge is characteristically less abrupt than its onset, and the experiments may have wrongly assessed the endpoint of the discharges.

AUTONOMIC VARIABLES Pulse and respiration rates were counted for the first, fifth, tenth, fifteenth, and twentieth minutes of each test situation and these values were examined for significant 'withinsituation' trends. None were found, and a mean pulse rate and respiration rate were calculated for each test period each day. In both patients the mean pulse rate during the 5-lights test was each day faster than during the tape test, and faster than the resting value. There was no significant difference between the resting pulse rate and the pulse rate during the tape test. The mean respiration rate during the 5-lights test was for both patients faster than the resting value, and in the case of A.S. was faster each day than during the tape test. In the case of C.M. the mean respiration rate during the 5-lights test was significantly faster than during the tape test $(\mathrm{t}=2.58, \mathrm{P}<0.05)$. 
PATIENTS' ATtITUDE TO TESTS Both patients reported that they enjoyed working at the 5-lights test, and both complained that during the tape test they felt drowsy and found difficulty in concentrating.

\section{FURTHER EXPERIMENTS ON EFFECT OF DIFFERENT TEST SITUATIONS ON WAVE-SPIKE ACTIVITY}

An attempt was made with A.S. to discover the factors responsible for the reduction in the number of wave-spike discharges during the performance of the 5-lights test. An experiment was set up to determine whether the continuous motor activity or the intermittent visual stimuli associated with the test were essential for the reduction of wave-spike discharges. Initial and final resting records were obtained as previously described, and the duration in seconds of wave-spike discharges recorded compared with two intermediate test periods. In the first of these the subject was asked to watch carefully while the experimenter carried out the 5-lights test. In the second, the lights were disconnected and the subject was asked to keep working at the test, pressing alternately the centre button and any of the peripheral buttons. This experiment was repeated on four occasions, the order of the tasks being alternated each time. A large and significant reduction in wave-spike discharge occurred in both test situations with respect to total amount recorded and to the duration of individual bursts (Table III).

\section{TABLE III}

WAVE-SPIKE DISCHARGES AND OTHER TEST SITUATIONS

\begin{tabular}{llll} 
& $\begin{array}{l}\text { Watching } \\
\text { 5-Lights Test }\end{array}$ & $\begin{array}{l}\text { Performing Test } \\
\text { without Lights }\end{array}$ \\
\hline Total seconds of wave-spike & 174 & $\quad \begin{array}{l}175 \\
\text { F }=8.9 \mathrm{p}<0.01\end{array}$
\end{tabular}

It had been noted that a similar reduction of wave-spike occurred during periods of conversation, and it was postulated that the important variable involved was the alertness of the patient. As a test of this hypothesis, and as a further test of the importance of modality of stimulus, an experiment was set up using a television set. Four conditions of stimulation were presented, namely, sound only, picture only, picture and sound, neither picture nor sound. A Latin square design was used, each condition being presented for one minute on any particular occasion. It was found that a significant reduction in wave-spike occurred only when both picture and sound were presented together (Table IV).

Mean pulse and respiration rates were on each occasion faster than at rest when the patient was
TABLE IV

WAVE-SPIKE DURING TELEVISION EXPERIMENT

\begin{tabular}{lc} 
Condition & Wave-spike Discharge (sec.) \\
\hline No light or sound & 94 \\
Picture only & $80\} \mathrm{t}=2 \cdot 1 \mathrm{~N} . \mathrm{S}$. \\
Sound only & 99 \\
Picture and sound & 41 \\
& $\mathrm{~F}=21.12 \mathrm{p}<0.001$
\end{tabular}

watching the experimenter do the 5-lights test and when she did it herself with the lights disconnected. There was no significant difference between mean pulse rate and respiration rate during the four television conditions, which were, however, presented for only one minute at a time.

\section{DISCUSSION}

Consistent differences have been found in the amount of wave-spike which was recorded from two epileptic patients during different activities. Attempts to uncover the significant variables in the reduction of discharges during the 5-lights test weree unsuccessful, in that it made no difference whethee the subject was continuously occupied in pressing buttons with the lights disconnected or merel 8 watched someone else pressing them. From a experiment with a television set it appeared that modality of stimulus, as between visual and auditoryo was of no significance. However, in all situations. described by the subject as 'interesting' wave-spike discharges were fewer and briefer than at rest. By contrast both patients complained of difficulties in concentration and feelings of drowsiness during the tape test, when significantly more wave-spike activity was recorded than at rest.

It is attractive to postulate that these variations in wave-spike activity were related to changes in awareness. Subcortical discharges are often said to be more liable to occur during drowsiness, and Lennox and Lennox (1961) state that petit mal attacks are less frequent when the patient is kept occupied. Appropriate and significant changes in the autonomic measures used occurred during all the situations described by the patients as interesting, except during the television experiment. However, there was no objective evidence of drowsiness during the tape test. Pulse and respiration did not slow, no significant changes in background activity could be seen on visual inspection of the E.E.G. tracing, and very few errors of omission, which are known to increase during drowsiness, were made. It seems likely that the relevant factor in the increase of wave-spike discharges was the state of divided attention or the feeling of boredom which the test 
induces. The findings may be considered to have therapeutic interest in suggesting the importance of psychological factors in the control of epilepsy. Further experimental work is clearly needed, together with some better method of analysing and quantifying changes in E.E.G. background activity.

The observations reported here of test responses during spontaneous wave-spike discharges may throw some light on the conflicting results of other studies. It appears that the particular measure considered and the duration of wave-spike discharges are relevant variables, and that marked differences between individuals may occur. The most sensitive correlate of wave-spike discharges was found to be response time, which slowed significantly during wave-spike discharges of $\frac{1}{2}$ to $1 \frac{1}{2}$ seconds. No increase in errors of omission occurred during discharges of this duration, but in longer discharges both patients increased their errors of omission. One patient made more errors on both tests during wave-spike discharges than the other.

Certain practical implications arise from this study. The possible handicap of brief wave-spike discharges should be considered when assessing the performance of epileptics on 'paced' tasks, e.g., timed intelligence tests, even though no seizures are observed or reported by the patient. It may also be important to investigate the effect of slowed responses during brief wave-spike discharges on such skills as car driving. On the other hand, in an unpaced task, working at their own rate, the epileptics in our study were able to compensate for the effect of quite large numbers of wave-spike discharges. This was possible because their response times between discharges did not increase even when half the recording time was occupied by them.

Finally, it seems legitimate on the basis of this and other studies to question the validity of the traditional distinction between seizures and inter-seizure paroxysmal discharges. We would argue that the slowing of a response time or an error made during testing should be considered evidence of a seizure when accompanied by appropriate E.E.G. changes, even though nothing has been detected by routine clinical observation. Electroencephalographic investigations may then be considered of greater relevance to the investigation of petit mal epilepsy, since wavespike discharges can be used as a quantitive measure of seizure activity.

\section{SUMMARY}

A study is described of changes in the amount of wave-spike discharge recorded from epileptics during the performance of various tests, and of changes in test performance during the occurrence of such brief discharges. Consistent differences were found between the amount of wave-spike discharge recorded from two epileptic patients during rest periods and during the performance of tests.

Further experiments with one patient suggested that alertness was an important factor associated with the reduction of wave-spike. Both the patients worked more slowly and made more errors during discharges than between them. Wave-spike discharges lasting only $\frac{1}{2}$ to $1 \frac{1}{2} \mathrm{sec}$. were accompanied by significantly slower response times.

There was no evidence that the occurrence of even a large amount of wave-spike impaired performance between discharges.

This work was carried out while the first author was in receipt of a grant from the Medical Research Council. We are very grateful to the British Epilepsy Association for a grant from their research funds. We wish to thank Professor G. Dawson and Dr. D. A. Pond for their encouragement and help, and Dr. D. W. Liddell for permitting us to study his patients. We are also much in debt to the staff of the E.E.G. department and to the Maudsley Hospital nursing staff for their assistance, and to Mr. P. St. John Loe for making and maintaining our apparatus.

\section{REFERENCES}

Cornil, L., Gastaut, H., and Corriol, J. (1951). Rev. neurol., 84, 149. Kiloh, L. G., and Osselton, J. W. (1961). Clinical Electroencephalography. Butterworths, London.

Kooi, K. A., and Hovey, H. B. (1957). A.M.A. Arch. Neurol. Psychiat., $78,264$.

Lennox, W. G., with Lennox, M. A. (1960). Epilepsy and Related Disorders. Little, Brown, Boston.

Milstein, V., and Stevens, J. R. (1961). J. nerv. ment. Dis., 132, 50.

Mirsky, A. F., Primac, D. W., Marsan, C. A., Rosvold, H. E., and Stevens, J. R. (1960). Exp. Neurol., 2, 75.

Pond, D. A. (1961). Brit. med. J., 2, 1377.

Prechtl, H. F. R., Boeke, P. E., and Schut, T. (1961). Neurology (Minneap.), 11, 296.

Schwab, R. S. (1941). Amer. J. Ps, chiat., 97, 1301.

Wilkinson, R. T. (1958). Medical Research Council's A.P.R.U. Res. Report, No. 323/58.

Williams, H. L., Lubi n, A., and Goodnow, J. J. (1959). Psychol. Monogr., 73, No. 14 [Whole No. 484]. 